\title{
PRAGMATIC MARKERS IN EUGENE O'NEILL'S ILE: DISCOURSE COHERENCE RELATIONS
}

\author{
Riza Astutie ${ }^{1}$, Rommy D. B. Rambet ${ }^{2}$ \\ Universitas Negeri Surabaya (UNESA) ${ }^{\mathbf{1}}$, Universitas Cendrawasih Jayapura ${ }^{\mathbf{2}}$ \\ rizaastutie@gmail.com ${ }^{\mathbf{1}}$,rommydanny@yahoo.com ${ }^{2}$
}

\begin{abstract}
This study aimed to investigate the types of pragmatic markers in a drama entitled Ile. The study is based on Fraser's theories of pragmatic markers and discourse coherence relations. This research employs a descriptive qualitative research method since the presentation of the results of the analysis is in the form of tabulation and description of the data. The present study employs one of those three kinds of triangulation suggested by Miles and Huberman that is expert triangulation. The results of the analysis of the data indicate that from 4,369 words in the drama, 415 linguistic items are identified as pragmatic markers which are distributed into four major types of pragmatic markers: basic markers (159 items), commentary markers (5 items), parallel markers (121 items), and discourse markers (130 items). Coherence relations which are found in drama Ile shows that those pragmatic markers provide the bridge between the propositional parts of the discourse that making it possible for the characters in drama to move quickly and smoothly from one topic to another.
\end{abstract}

Keywords: pragmatic markers; discourse coherence relations.

\section{INTRODUCTION}

In the process of communication, both addresser and addressee are always in a state of interpretation and transmission. Hence, the need to signal one's communicative intention in social interaction and direct the addressee's intention on the goal and the need of the hearer to acknowledge the speaker are inherent in human interaction. Thus, every human language provide ways in which such communicative needs can be satisfactorily connected. Schiffrin (1987:318) suggests that interpretation process of the hearer is guided by the use of markers because markers select a meaning relation from whatever potential meanings are provided through the content of talk and display that relation.

Moreover, Schiffrin (1987) continues by stating that there is a category of words which aid in conversation not by their semantic meaning, but in some other way. They can be single words such as oh, ah, and well or colloquial phrases like I mean like and you know or rhetorical questions, such as .....aren't they?. Those words or phrases relatively syntaxindependent and tend not to have a specific semantic meaning, but contribute pragmatic function. It means those lexical items function as index devices that work as 'contextual coordinates of talk'. They will here be referred to as pragmatic markers. These markers establish a relation that reflects the participants' intentions, presuppositional value and illocutionary meaning of the sequence. 
Related to this study, the researcher wants to analyze pragmatic markers in one of O'Neill's works, entitled Ile. Ile is drama which tells about conflict in the ice-locked ship. But, actually, there is another significant story brought by the major characters in drama Ile, that is about relationship between husband (Captain Keeney) and wife (Annie). The existence and correspondence of pragmatic markers in Ile will also give a clue to find the intended meaning of character's utterances (in this case, Annie's utterances and Captain Keeney's utterances), since they are cues used by the speaker to signal his/her intentions, to convey illocutionary force to the discourse, to focus the hearer's attention onto a specific contextual space, and to facilitate and restrict the hearer's possible inferences for interpreting the message.

The researcher chooses Ile, since this drama is unique in which there is significant story beyond surface story. Here, throughout the conflict in the ship, O'neill tries to show another conflict between Mrs. Keeney (Annie) and Captain Keeney. The conversation between characters is interesting to analyze because the story has two conflicts that will be comprehended by analyzing utterances which consist pragmatic markers. Those pragmatic markers can focus the hearer's attention onto a specific contextual space, and to facilitate and restrict the hearer's possible inferences for interpreting the message.

\section{REVIEW OF LITERATURE}

\subsection{Classification of Pragmatic Markers}

Fraser (1966:167) takes pragmatics as an account of the process by which the language user takes a sentence representation provided by the grammar and given the context in which the sentence is uttered, determines what messages and what effects the speaker has conveyed. In this case, there is a part of that process, namely, the ways in which the linguistically encoded information of sentence meaning provides an indication of the direct, literal messages intended by the speaker. This linguistically encoded clues which signal the speaker's potential communicative intentions are called pragmatic markers. Moreover, Fraser categorized pragmatic markers into four major types: basic, commentary, parallel and discourse. Detailed explanation of the types of pragmatic markers is summarized as follows.

\subsubsection{Basic Markers}

The first type of pragmatic markers is basic markers. Basic markers have representational meaning which means they contribute conceptual information. Specifically, they represent 
information which signals the force of the direct basic message of the sentence (Fraser, 1996:169-179).

\subsubsection{Commentary Pragmatic Markers}

The second type of pragmatic markers is commentary pragmatic markers. Fraser (1996:179) states that these markers are lexical expressions which have both representational meaning and procedural meaning. Representational meaning specifies an entire message, while procedural meaning signals that this message is to function as a comment on some aspect of the basic message. In this case, the message conveyed by commentary pragmatic markers is typically general rather than specific. Some examples of commentary pragmatic markers are illustrated as follows:

$>$ Frankly, we are lost.

$>$ Stupidly, we got lost.

$>$ Reportedly, you are in deep trouble.

$>$ I insist that we are not lost.

Moreover, Fraser (1996:180) explains that hedges such as technically, ideally literally, officially, theoretically, are excluded as commentary pragmatic markers.

\subsubsection{Parallel Markers}

The third type of pragmatic markers is parallel markers. Fraser (1996:185-186) states that parallel markers signal an entire message in addition to the basic message.

\subsubsection{Discourse Markers}

Discourse markers are the last type of pragmatic markers. Fraser (1996:186) states that discourse markers signal the relationship of the basic message to the foregoing discourse. Different from the other types of pragmatic markers, discourse markers do not contribute to the representative sentence meaning, but only to the procedural meaning. They provide instructions to the addressee on how the utterance to which the discourse marker is attached is to be interpreted.

\subsection{Discourse Coherence Relations}

While dealing with different aspects of discourse interpretation, the answers to these questions have to deal with how different people see verbal interaction as a meaningful whole, i.e. how they derive coherence from discourse. In recent years it has been possible to witness a considerable shift in the ways coherence is understood, namely a shift from a static text- 
based descriptive approach, according to which coherence is the product of textual connectivity and cohesion, to a more dynamic understanding, according to which coherence is conceptualized as a potentially variable cooperative achievement of the speaker/writer and the hearer/reader and can be seen as context-dependent, hearer/reader-oriented and comprehension-based, interpretative notion (Bublitz, 1999:1-7).

Discourse coherence falls under context-relative language and has to do with how discourse relates to other discourse. As seen from the extract beginning the article pragmatic markers have the discourse-deictic function to mark a transition from one part of the dialogue to another (e.g. from an initiating move to a response or from one topic to another). They provide the bridge between the propositional parts of the discourse making it possible for the conversationalists to move quickly and smoothly from one topic to another. Discourse coherence is the result of interaction and cooperation. It involves both topical continuity and speaker change.

The presence of markers is necessary to make the type of relationship established between preceding and following propositions explicit and clear. The example used by Schiffrin (1987:318) can illustrate the key function of markers in a text may help to support such claim:

a. Sue dislikes all linguists.

b. I like her.

Paraphrasing Schiffrin's words, without any marker heading utterance (b), interpretations are opened to different options: if the person who reads or hears such interaction is a linguist or likes linguists, s/he will interpret that between (a) and (b) there is relationship of contrast and, therefore, there should be a but heading (b); if such is not the case, there should be a so establishing a cause-consequence relationship. Clearly, the meaning of both utterances is open enough to two or more possible interpretations and only its context will provide us with the correct one. The presence of marker between (a) and (b) utterances is not strictly essential but it becomes necessary to clarify the type of relationship set up, with all the inferences derived from it.

It can be concluded that markers have fundamental illocutionary, inferential and textstructuring functions, with minimal propositional content and no syntactic restriction. Furthermore, their presence facilitates the sort of coherence relations set up in a discourse (Gonzáles,2004:45). 


\subsection{Previous studies}

Other studies on the topic of pragmatic markers have also been conducted. The first is Andersen (2001) who conducted a research Pragmatic markers and Sociolinguistic Variation. This study focused on variation across generations of speakers and the effect of age differences on the language of speakers. The second study on pragmatic markers was conducted by Erkan Yilmaz in 2004 in Turkey. Adopting an eclectic analytic perspective of discourse analysis, conversation analysis and functional approaches, this study conducts an in-depth pragmatic analysis and describes the function of three pragmatic particles yani, işte and şey in casual, conversational Turkish. All three particles have multiple functions, which are described by reference to occurrences in utterances within three different domains of conversation. While utterance initial occurrences of yani are mainly connective and continuative, the utterance final placement of yani mainly acts as a situating particle with a strongly interactional nature. The utterance medial occurrences are basically 'self-editing' whereby the speaker marks the clarification of a point in his/her prior talk. Isşte mainly acts as a frame particle demarcating utterances as containing detailed, highlighted, and reported information as well as connecting distant pieces of utterances. The third particle şey basically marks the speaker's temporary mental effort of extracting the linguistic information from the memory. In addition to its major role in repair organisation whereby marking its producer's verbal planning and word search, şey displays caution and discretion and marks politeness when assessing/asserting something about the self or the other.

Third related previous study is entitled Two Accounts of Discourse Markers in English. This study was conducted by Miri Hussein. This study is a scrutiny of the semantics and pragmatics of discourse markers in English. It discusses two accounts in the analysis of discourse markers, namely the Coherence account and the Relevance account. The study investigates the similarities and differences between the two accounts.

Another related previous study is entitled Ojibwe Discourse Markers. This study was conducted by Brendan George Fairbanks in 2009. This study describes the functions of a variety of discourse markers in the Ojibwe language, a language belonging to the Algonquian family of languages of North America. This study shows that her initial characterization by Schiffrin (1987) must be broadened in order to account for languages such as Ojibwe which show discourse markers occurring in both initial and second position, and for other languages which show discourse markers occurring in medial and final positions. Also, since many languages like Ojibwe and the Amazonian languages examined in this study make regular use 
of clitics and affixes as discourse markers, this related previous study shows that not all discourse markers are 'detachable' from their containing sentences.

\section{RESEARCH METHODS}

This research employs a descriptive qualitative research method since the presentation of the results of the analysis later is in the form of tabulation and description of the data. This research is more interpretative rather than theoretical and based on the linguistic reality of the use of pragmatic markers in the story (i.e., drama) being analyzed. The data of this research is taken from the drama, focused on the part of conversation among all characters in the drama. The primary data of this research are the linguistic items which are categorized as pragmatic markers and they are derived fully from the drama Ile. The data are then grouped in a corpus type of pragmatic markers in readiness for analysis. In collecting the data, researcher selects data in the forms of a list of words, phrases and clauses which have been categorised as pragmatic markers. To ease the processes of identifying and classifying the data, the linguistic items which are categorized as pragmatic markers are coded and labeled systematically. The coding systems applied in this study follow the number of clauses after the drama Ile is rendered. The present study employs one of three kinds of triangulation suggested by Miles and Huberman (1994: 26) that is expert triangulation. In this case the researcher does crosschecking the interpreted data to the experts to minimize the subjectivity and bias of the interpretation. The experts are the researcher's supervisors in doing this research, they are Prof. Abbas A. Badib, MA., MA., Ph. D and Drs. Suwono, BA., Ph. D.

The analysis of data is conducted through some stages. The first stage is the identification of all linguistic devices that are categorized as pragmatic markers. The identification of the markers is then followed by the tabulation of the markers in accordance to the types, code, frequency and percentage. The final stage is the analysis of types, functions, and the contribution of each of the pragmatic markers to the coherence relation in the drama.

The analysis of the types of pragmatic markers here is done through some step. First step is classifying the markers into simple, compound and clausal. Next step, each marker within each category is then classified into the types of pragmatic markers, based on Fraser's (1996) classification, into basic, commentary, parallel, and discourse. Finally, the analysis of the contribution of pragmatic markers to the coherence relation in the drama is based on the principle that the presence of pragmatic markers facilitates the sort of coherence relations set up in a discourse (Gonzáles, 2004:45). 


\section{RESULTS AND DISCUSSION}

\subsection{Pragmatic Markers in Ile}

The conversation in drama (Ile) being analyzed in this thesis consists of about 4,369 words which are then grouped into 484 clauses. Of these figures of words and clauses, 415 linguistic items are identified as pragmatic markers which are distributed into four major types of pragmatic markers following Fraser's (1996) identification of the types of pragmatic markers in English. Then, these pragmatic markers are tabulated according to the membership of the markers in the groups of the four types of markers, followed by the frequency and percentage scales. The goal of organising and tabulating the pragmatic markers in such a way is to see how often a specific marker is used in the drama.

\subsubsection{Basic Markers in Ile}

The identification of pragmatic markers is followed by an interpretation and conclusion when each major type of markers is discussed. As a starting point, let us consider the 'basic' pragmatic markers which are found in the Ile as they are presented in table 1.

Table 1: Basic Markers in Ile

\section{Types of pragmatic Examples of Basic Markers markers}

1) Structural basic markers
a) Declarative
I mean..., I'll thank you...., I know..., I warned ..., I
21

guess ..., I feel ..., I'm afraid..., I heard ..., I tell ye

b) Imperative Stay by the stove where ye belong

and ye'll find no need of chatterin'.

Get out o' this, you!

Clean up the chart room

c) Interrogative

What're ye shiverin' 'bout?

Who d'ye think it were- the Old Man?

Where was it ye've been all o' the time-the

fo'c'sle?

What is it he thinks he's goin' to do?

\section{2) Lexical Basic Markers}
a) Performative
Expressions
I reckon

2

b) Pragmatic Idioms Oh, Yes / Aye, No, Aw, Damn, Ah

3) Hybrid Basic Markers

a) Declarative-based Hybrids 


\begin{tabular}{clc}
\hline$\sim$ Tag question & $\ldots$, be you, ...? ..., wouldn't it? ..., wasn't it? ..., & 14 \\
$\sim$ Positive tag & don't you? \\
question & $\ldots$, haven't I, .., .., be you? ..., don't ye? ..., is it? & \\
& $\ldots$, ain't you? .., have I? & \\
\hline $\begin{array}{c}\text { b) Interrogative- } \\
\text { based Hybrids }\end{array}$ & Won't you please turn back? & 1 \\
\hline $\begin{array}{c}\text { c) Imperative-based } \\
\text { Hybrids }\end{array}$ & None o' your lip, .., or I'll learn ye & 1 \\
\hline
\end{tabular}

Table 1 indicates that 159 (38.31\%) linguistic items of the whole number of pragmatic markers (415 linguistic items) in the drama Ile are identified as basic pragmatic markers. From table 1, it can be seen that the dominant use of basic markers is the use of message idioms which is the member of pragmatic idiom type in lexical basic marker group. The figure of the dominant use of that type suggests that the delivery of the story of this drama is emphasized on the use of the pragmatic markers to signal the entire basic message of the characters' utterances.

\subsection{Commentary Markers in Ile}

The identification of pragmatic markers, in this thesis, is followed by an interpretation and conclusion when each major type of markers is discussed. As a starting point, let us consider the number, frequency and percentage of commentary markers which are found in the Ile as they are presented in table 2.

Table 2: Frequency Scale of Commentary Markers in Ile

\begin{tabular}{llc}
\multicolumn{1}{c}{ Types of pragmatic markers } & Examples of Commentary Markers & Freq \\
1) Assessment markers & Rightly & 1 \\
\hline 2)Manner-of-speaking markers & You know & 1 \\
\hline 3) Hearsay markers & & 2 \\
\hline 4) Emphasis markers & They say..., You said .... & 1 \\
\hline
\end{tabular}

Table 2 indicates that $5(00.12 \%)$ linguistic items of the whole number of pragmatic markers (415 linguistic items) in the drama Ile are identified as commentary markers. The use of this type of pragmatic markers in the drama seems to be dominated by hearsay markers ( 2 linguistic items). Markers which belong to hearsay markers are comments about the type of source of the speaker's information.

It is also identified in the above table that 1 pragmatic marker belongs to assessment marker signals the speaker's evaluation of the state of the world represented in the proposition. It is also found 1 pragmatic marker belongs to manner-of-speaking marker which 
signals the speaker's comment on the manner in which the basic message is being conveyed, and 1 pragmatic marker belongs to emphasis marker which emphasizes the force of the basic message. Meanwhile, it is found that there is no pragmatic markers which belong to the group of mitigation markers evidential markers and consequent-effect markers.

\subsection{Parallel Markers in Ile}

The identification of pragmatic markers, in this thesis, is followed by an interpretation and conclusion when each major type of markers is discussed. As a starting point, let us consider the number, frequency and percentage of parallel markers which are found in the Ile as they are presented in table 3 .

\section{Table 3: Frequency Scale of Parallel Markers in Ile}

\section{Types of pragmatic markers $\quad$ Examples of Parallel Markers}

Freq

1) Vocative markers Young 'un, Mr. Steward, Sir, You, Mr. Slocum, Annie, David, Tom, Woman, Harpooner

2) Speaker displeasure Damn, To the devil with ...! for my sake, for markers God's sake, For the love of God, for your sake

3) Focusing markers Well, now, You see,

Table 3 indicates that $121(29.16 \%)$ linguistic items of the whole number of pragmatic markers (415 linguistic items) in the drama Ile are identified as parallel markers. The use of this type of pragmatic markers in the drama seems to be dominated by vocative markers. It is shown in the table 3 that 101 pragmatic markers in drama Ile belong to vocative markers. The vocative markers which is found in this drama include standard titles, occupation name, general nouns, and pronominal forms. In this case, the use of vocative marker in character's utterances shows that a speaker is explicitly sending the message that the addressee of this message is person who has been mentioned in vocative markers.

It is also identified in the above table that 13 pragmatic markers belong to the speaker displeasure markers. These markers signal a message of the speakers expressing annoyance, but it is not usually clear whether the addressee or the situation is the target of the anger. Turn to the next group of parallel markers, that is called focusing markers. It can be shown in table 3 that 7 pragmatic markers belong to these markers. Focusing markers signal focusing or refocusing on the topic at hand. Meanwhile, from the four types of parallel markers, solidarity markers are not found in the drama Ile.

\subsection{Discourse markers in Ile}

The identification of pragmatic markers, in this thesis, is followed by an interpretation and conclusion when each major type of markers is discussed. As a starting point, let us consider 
the number, frequency and percentage of parallel markers which are found in the Ile as they are presented in table 4.

Table 4: Frequency Scale of Parallel Markers

\begin{tabular}{llc}
\multicolumn{1}{c}{ Types of pragmatic markers } & \multicolumn{1}{c}{ Examples of Discourse Markers } & $\begin{array}{c}\text { Fre } \\
\mathbf{q}\end{array}$ \\
\hline 1) Contrastive markers & But, yet/yit, instead of/instead, & 22 \\
\hline 2) Elaborative markers & and / 'n' / an', or, & 98 \\
\hline 3) Inferential markers & Then, & 10
\end{tabular}

Table 4 indicates that $130(31.33 \%)$ linguistic items of the whole number of pragmatic markers (415 linguistic items) in the drama Ile are identified as discourse markers. The use of this type of pragmatic markers in the drama is dominated by elaborative markers. In this case, the utterance which follows elaborative marker constitutes a refinement of some sort on the preceding discourse. It is also found that 22 pragmatic markers are identified as contrastive markers. The utterance which follows the contrastive marker is either a denial or a contrast of some proposition associated with the preceding discourse.

It is also identified in the above table that 10 pragmatic markers belongs to inferential markers. These markers signal that the force of the utterance is a conclusion which follows from the preceding discourse. Meanwhile, it is found that there is no pragmatic markers which belong to the group of topic change markers.

\subsection{Contribution of pragmatic markers to the coherence relation in Ile}

Discourse coherence falls under context-relative language and has to do with how discourse relates to other discourse. As seen from the extract beginning the article pragmatic markers have the discourse-deictic function to mark a transition from one part of the dialogue to another (e.g. from an initiating move to a response or from one topic to another). They provide the bridge between the propositional parts of the discourse making it possible for the conversationalists to move quickly and smoothly from one topic to another. Discourse coherence is the result of interaction and cooperation. It involves both topical continuity and speaker change.

The presence of markers is necessary to make the type of relationship established between preceding and following propositions explicit and clear. It can be illustrated by the conversation between Mrs. Keeney and Mr. Keeney in situation when she attempts to 
convince her husband (Mr. Keeney) to go for home and persuades him not to continue the sail for getting the ile anymore. The conversation between them can be shown as follows:

Mrs Keeney : Yes, you were very kind, David. I know that. I won't stand it. Ican't stand it — pent up by these walls like a prisoner. Take me away from here, David! If I don't get away from here, out of this terrible ship, I'll go mad! Take me home, David! I can't think any more. I feel as if the cold and the silence were crushing down on my brain. I'm afraid. Take me home!

Keeney $\quad$ : Best go to bed, Annie. You ain't yourself. You got fever. Your eyes look so strange like. I ain't never seen you look this way before.

The bold and italic phrase I feel in the conversation above is identified as declarative structure of structural basic marker. In this case, by uttering I feel as if the cold and the silence were crushing down on my brain (clause 309-310) Mrs. Keeney is committed to express the belief of her feeling that the cold and the silence arround the ship are as if crushing down on her brain. It can be said that the kind of coherence relation which is identified in Mrs. Keeney's utterances include relationship of belief expression. This relationship is reflected by the use I feel as declarative structure of structural basic marker. The kinds of coherence relations which are identified in Ile include relationship of belief expression which is reflected by the use of declarative structure of structural basic marker.The use of imperative structure of structural basic markers can reflect relationship of strong desire expression.

Meanwhile, relationship of desire expression of verbal response is reflected by the use of interrogative structure of structural basic markers. Performative expressions of lexical basic markers which are found in drama Ile reflect relationship of basic message force. Meanwhile, pragmatic idioms of lexical basic markers reflect relationship of entire basic message. Besides, declarative-based hybrids of hybrid basic markers which are found in that drama reflect relationship of confirmation request and relationship of tentative conclusion confirmed. Interrogative-based hybrids of hybrid basic markers reflect relationship of action request. Meanwhile, imperative-based hybrids of hybrid basic markers reflect relationship of order. All these relationships are reflected by the use of basic markers.

Commentary markers which are found in drama Ile also reflect many kinds of coherence relations, such as relationship of assessment which are reflected by the use of assessment marker. Manner-of-speaking markers reflect relationship of manner-of-speaking. Meanwhile, hearsay markers of commentary markers in that drama reflect relationship of hearsay. Emphasis marker of commentary marker reflects relationship of emphasis. 
Parallel markers which are found in drama Ile also reflect many kinds of coherence relations. Vocative markers of parallel markers which are found in that drama reflect relationship of explicit sending message. Relationship of speaker displeasure are also found in the use of speaker displeasure markers. Meanwhile, focusing markers found in that drama reflect relationship of refocusing and relationship of focusing.

The kinds of coherence relations which are reflected by the use of discourse markers include relationship of contrast as in clause 21 (as an example): nothin' to see but ice. This relationship is reflected by the use of contrastive marker but. Besides, the use of yet/yit and instead of/instead also reflect relationship of contrast. It can be shown in clause 93 (and this truck not cleared yet) and clause 288 (and instead, all I find is ice and cold and brutality!). Relationship of elaboration is reflected by the use of elaborative markers as in clause 431: and we'll drive her through. The marker or as elaborative marker also reflects relationship of elaboration as in clause 8: or must we drag 'em out?. Meanwhile, inferential marker of discourse markers which is found in drama Ile reflect relationship of conslusion. This relationship is reflected by the use of then in clause 155: Then you ain't goin'-to turn back?.

From the brief explanation about coherence relations which are found in drama Ile, it shows that those pragmatic markers provide the bridge between the propositional parts of the discourse that making it possible for the characters in drama to move quickly and smoothly from one topic to another.

\section{CONCLUSION}

As a literary work, Ile has become interesting drama since its story has significant conflict brought by the major characters (Captain Keeney/David and Mrs. Keeney/Annie). Conflict brought by those major characters appears in the middle of conflict of ice-locked ship. It can be said that this drama is unique in which there is significant story beyond surface story. The conversation between characters is interesting to analyze because the story has two conflicts that will be comprehended by analyzing utterances which consist pragmatic markers. Those pragmatic markers can focus the hearer's attention onto a specific contextual space, and to facilitate and restrict the hearer's possible inferences for interpreting the message. The conversations among characters move quickly and smoothly from one topic to another because of the existence and correspondence of pragmatic markers which are found in the drama.

This study is conducted to identify the types of pragmatic markers in Eugene O'Neill's drama Ile, based on Fraser's theory of pragmatic markers. Fraser (1996) categorized 
pragmatic markers into four major types which include (a) basic markers, (b) commentary markers, (c) parallel markers, and (d) discourse markers. The finding of the types of pragmatic markers in drama Ile will give a clue to analyze the functions of the use of pragmatic markers in that drama.

Based on the analysis of pragmatic markers include its functions and its contribution to coherence relations as outlined in this study, the researcher draws some conclusion as follows; First, the results of the analysis of the data indicate that from 4,369 words in the drama, 415 linguistic items are identified as pragmatic markers which are distributed into four major types of pragmatic markers: basic markers, commentary markers, parallel markers, and discourse markers. The identification of the types of pragmatic markers in drama Ile indicates that the use of the items of basic pragmatic markers is very dominant with 159 items (38.31\%). This is followed by the use of the items of discourse markers with 130 items (31.33\%), parallel markers with 121 items $(29.16 \%)$, and the least one is commentary markers with 5 items $(00.12 \%)$.

Second, basic markers found in drama Ile reflect many kinds of coherence relations include relationship of belief expression, relationship of strong desire expression, relationship of desire expression of verbal response, relationship of basic message force, relationship of entire basic message, relationship of confirmation request, relationship of tentative conclusion confirmed, relationship of action request, relationship of order. Commentary markers which are found in drama Ile also reflect many kinds of coherence relations, such as relationship of assessment, relationship of manner-of-speaking, relationship of hearsay, relationship of emphasis. Parallel markers which are found in drama Ile also reflect many kinds of coherence relations, such as relationship of explicit sending message, relationship of speaker displeasure, relationship of refocusing and relationship of focusing. Discourse markers which are found in drama Ile also reflect many kinds of coherence relations, such as relationship of contrast, relationship of elaboration, relationship of conslusion. Coherence relations which are found in drama Ile shows that those pragmatic markers provide the bridge between the propositional parts of the discourse that making it possible for the characters in drama to move quickly and smoothly from one topic to another.

\section{REFERENCES}

Andersen, Gisle. (2001). Pragmatic Markers and Sociolinguistic Variation: A RelevanceTheoretic Approach to the Language of Adolescents. Amsterdam: John Benjamins. 
Bublitz, Wolfram. (1999)."Introduction: Views on Coherence." In Coherence in Spoken and Written Discourse. How to Create it and How to Describe it, edited by Wolfram Bublitz, Uta Lenk and Eija Ventola, Amsterdam/Philadelphia: John Benjamins, 1-7

Fraser, Bruce. (1996). Pragmatic markers. Pragmatics, 6, 167-190.

González, M. (2004). Pragmatic Markers in Oral Narrative. Amsterdam: John Benjamins Publishing Company.

Miles, Matthew and Huberman, A. Michael. (1994). Qualitative Data Analysis: An Expanded Sourcebook. Thousand Oaks: Sage Publication, Inc.

Schriffrin, D. (1987). Discourse Markers. (Studies in Interactional Sociolinguistics, 5). Cambridge: Cambridge University Press. 